\title{
Primary versus deferred ureteroscopy for management of calculus anuria: a prospective randomized study
}

\author{
Ahmad A. Elderwy, Mohamed Gadelmoula, Mohammed A. Elgammal, Diaa A. Hameed,
} Hosny M. Behnsawy, Mahmoud M. Osman, Adel Kurkar

Assiut University, Urology and Nephrology Hospital, Assiut, Egypt

Citation: Elderwy AA, Gadelmoula M, Elgammal MA, et al. Primary versus deferred ureteroscopy for management of calculus anuria: a prospective randomized study. Cent European J Urol. 2018; 71: 462-466.

Article history

Submitted: Aug. 19, 2018

Accepted: Dec. 4, 2018

Published online: Dec. 27, 2018
Introduction Obstructive anuria can be managed by primary ureteroscopy (URS) or deferred URS after initial ureteral stenting. We want to compare the primary URS and deferred URS in the management of calculus anuria regarding the feasibility and clinical outcome.

Material and methods Between January 2012 and December 2014, 150 patients with anuria due to ureteral calculi were prospectively randomized according to the timing of ureteroscopic intervention into two groups; deferred URS group (69 patients who were treated initially by ureteral stenting) and primary URS group (81 patients who were treated by emergency URS). Follow-up was at least 6 months postoperatively.

Results Complete stone clearance was $87 \%$ and $75.3 \%$ for deferred and primary URS groups, respectively $(p=0.097)$. Renal function normalized in $94.2 \%$ of deferred URS vs. $97.5 \%$ of primary URS $(p=0.414)$. Deferred URS group had a $2.9 \%$ overall complication rate in comparison to $9.9 \%$ for the primary URS group ( $p=0.109)$. Ureteral perforation/pyelonephritis was noted in $6.2 \%$ of the primary URS group only $(p=0.043)$. The median number of maneuvers required until stone clearance was one (range 1-5) for primary URS vs. two (range $2-3$ ) for deferred URS $(p<0.001$ ). The cost of primary URS was significantly less ( $p<0.001)$. On a multivariate analysis, lower ureteral calculi (OR 13.03, 95\% Cl 4.07-41.7, p <0.001) and deferred URS (OR 2.84, 95\% Cl 1.07-7.49, $p=0.035$ ) were independent predictors for an eventless and successful URS.

Conclusions Primary URS for calculus anuria is feasible and cost-effective. It has a short hospital stay, but is still technically demanding. The perioperative complications are comparable to URS in normouric patients.

Key Words: acute renal failure «` anuria 〈〉 ureteral stone 〈 ureteroscopy

\section{INTRODUCTION}

In our locality, there is a high incidence of calculus anuria because of the high prevalence of stones $[1,2,3]$.

The inherent risk of anuria is the associated electrolyte imbalance, especially hyperkalemia, that could lead to cardiac dysrhythmia and sudden death. Therefore, imperative and urgent intervention must be considered. However, before making a decision of intervention we have to consider the availability of endoscopic experience and the instruments [4].
The role of ureteroscopy (URS) in the management of calculus anuria could be primary or deferred. The deferred URS after initial ureteral stenting or percutaneous drainage is the standard one. However, the remarkable progress in the manufacturing of ureteroscopes and lithotripters favored the primary URS [5].

In the current study, we want to evaluate the role of both primary and deferred URS in the management of calculus anuria with regard to the feasibility, clinical outcome, and the cost-effectiveness in a comparative manner. 


\section{MATERIAL AND METHODS}

Between January 2012 and December 2014, a total of 191 consecutive patients were assessed for eligibility of which 24 patients were excluded (because of the history of diabetes in 16 and chronic renal impairment in 6) and 17 declined to participate. The sample size was calculated using Epi Info ${ }^{\mathrm{TM}}$, version 3.5. To detect a $12 \%$ difference between the 2 groups with a $90 \%$ power and a threshold of significance of 0.05 , the sample size had to be 141 patients (74 in one group and 67 in the other). The primary endpoint was the improvement in the renal function namely blood urea nitrogen and serum creatinine after one month of interference. The secondary endpoints were the clinical outcomes of the procedures including the perioperative complications and the stone-free rates. Of the 150 patients included, patients with calculus anuria due to ureteral calculi (114 men and 36 women), 72 had a solitary kidney. Every patient was first subjected to a general examination to exclude signs of acidosis, sepsis or fluid retention. Laboratory investigations performed include serum electrolytes, serum creatinine, and blood urea. An arterial blood sample was taken to determine the level of blood gases. Abdominal ultrasound, plain x-ray (KUB) and non-contrast computed tomography (CT) were done to determine the degree and level of obstruction.

According to our standard protocol of managing patients who were critically ill (had serum creatinine $\geq 8 \mathrm{mg} / \mathrm{dl}$, serum potassium $\geq 7 \mathrm{mEq} / \mathrm{L}$ and/or blood $\mathrm{pH} \leq 7.1$ ) they were treated initially by hemodialysis. Subsequently, patients were prospectively quasirandomized for either primary URS or deferred URS according to the day of initial admission to the hospital. Patients admitted on odd days were subjected to urinary drainage through the insertion of a JJ stent first then a deferred URS was performed after clinical and laboratory value improvement was noted. Patients admitted on even days were subjected to primary URS. The deferred URS was done within 10 days of ureteral drainage provided that the renal function was improved, and the anuric state corrected. Ureteral dilatation was performed when stone size exceeded $10 \mathrm{~mm}$ to facilitate extraction of the fragments. Ureteroscopic lithotripsy was done using an 8.5 Fr (reaching $11 \mathrm{Fr}$ at the proximal end) semi-rigid Richard Wolf ureteroscope and a pneumatic lithotripter or holmium laser. The JJ stent was left for one week after lithotripsy. Postoperatively, the patients in both groups were monitored for diuresis, fever, hematuria and renal function improvement. They were discharged when they were clinically stable and their laboratory results were stable or improving.
KUB or CT (for radiolucent stones) was performed before stent removal to assess stone clearance. Abdominal ultrasound, serum creatinine, and plain KUB (for radiopaque stones) were done for all patients 3 months after removal of the ureteral stent. Normalization of renal function was defined as serum creatinine $\leq 1.4 \mathrm{mg} / \mathrm{dl}$ in males or $\leq 1.2 \mathrm{mg} / \mathrm{dl}$ in females. If there was any suspicion of renal backpressure, contrast study (intravenous urography/ CT urography) was done for ureteral stricture detection. The individual patient cost was calculated based on the cumulative sum of various costs. This included operating room costs (based on the type of operation, not the time of operation), operating room supplies (including anesthesia costs), professional fees, inpatient cost, and medications. The cost of stent removal, complications (that needed reoperation only), radiological and laboratory cost was excluded from cost analysis.

The statistical analysis was done using Intercooled STATA $^{\circledR}$, version 9.2. The patient and stone criteria, procedure details, outcome and complications of both groups were compared. Descriptive statistics, such as median and interquartile range (IQR) for continuous variables and proportions and frequencies for categorical variables, were used to analyze the data. Continuous variables were compared using the Mann-Whitney $U$ test with values shown as the median and IQR. Categorical variables were compared using the Pearson chi-square / Fisher exact test. Multivariate logistic regression analysis was used to identify variables independently associated with the stone clearances in two shock wave lithotripsy (SWL) sessions and a $\mathrm{P}$ value $<0.05$ was considered statistically significant.

\section{RESULTS}

The median patients' age was 34 years (range: 21 to 54) and the median duration of calculus anuria was 2 days (range: 1 to 6 ). Stone distribution was: $56 \%$ lower ureteral, $32 \%$ mid ureteral, and $12 \%$ upper ureteral. Median stone(s) length was $7 \mathrm{~mm}$ (range: 3 to 16). Primary ureteroscopy performed in 81 patients and deferred ureteroscopy in 69 patients. Patient characteristics are summarized in Table 1. There was no statistical difference between the two groups regarding the patients age, sex, stone criteria (level, laterality, multiplicity, and size), anuria duration and serum creatinine level.

Twelve patients were considered critically ill and underwent dialysis before intervention; 8 of them were subjected later to primary URS and 4 subjected to ureteric stenting (before deferred URS). This was 24 hours after the end of the dialysis session. There 
was no statistically significant difference in the perioperative outcome between patients with obstructed solitary kidney and those with bilaterally obstructed kidneys.

Six stones could not be reached during primary URS and so were considered as a failed ureteroscopies; two of these patients had upper ureteral stones with a ureteral kink, while four patients had mid ureteral stones with a tight lower ureter. All of them were stented and managed later by deferred ureteroscopy. Also, ureteral stenting failed in 5 patients due to the inability to negotiate the ureteral orifice, for them we inserted percutaneous nephrostomy (PCN) and underwent deferred ureteroscopy after improvement of the renal function. Algorism of patients' management and stone clearance is presented in Figure 1. As in regards to the initial stone clearance, there was no statistically significant difference between both groups $(\mathrm{p}=0.097)$. The median hospital stay at initial admission was 4 days (range: 3 to 8). Patients needed a median of 2 maneuvers (range: 1 to 5) until complete clearance. Noteworthy, the median hospital stay and the median maneuvers until stone clearance were significantly lower in the primary URS group $(\mathrm{P}<0.001)$. Two patients in the primary URS group and four patients in the deferred URS group did not achieve the normal serum creatinine level and their median baseline serum creatinine was $1.7 \mathrm{mg} / \mathrm{dl}$ (range: 1.5 to 1.9 ).

The overall complication rate in both groups was comparable, but ureteral perforation and pyelonephritis was significantly higher in the primary URS group $(P=0.043)$. We noticed minor ureteral perforation with urine extravasation in 5 patients in the primary URS group, consequently, the maneuver stopped, and a ureteral stent was inserted. Postoperatively, 3 of them developed pyelonephritis and were managed conservatively. The other 2 patients developed ureteral stricture and underwent laser ureterotomy.

The deferred URS was significantly higher in cost than the primary URS $(\mathrm{P}<0.001)$. The outcomes of both groups are summarized in Table 2. On multivariate logistic regression analysis, lower ureteral calculi and deferred URS were independent predictors for an eventless and successful URS as shown in Table 3.

\section{DISCUSSION}

Treatment of calculus anuria is considered one of the challenging problems in urology. Many factors should be considered during the management of such a condition. First of all, if it is related to a patient with critical illness and systemic sepsis, then minimally
Table 1. Characteristics of anuria patients who underwent either primary or deferred ureteroscopy (URS)

\begin{tabular}{|c|c|c|c|}
\hline & $\begin{array}{l}\text { Primary URS } \\
(\mathrm{N}=81)\end{array}$ & $\begin{array}{l}\text { Deferred URS } \\
\quad(N=69)\end{array}$ & $\mathrm{p}$ Value \\
\hline $\begin{array}{l}\text { Median age at treatment, years } \\
\text { (IQR) }\end{array}$ & $34(26,37)$ & $34(28,44)$ & 0.223 \\
\hline Females (\%) & 27.2 & 20.3 & 0.326 \\
\hline \multicolumn{4}{|l|}{ Location of ureteral stones (\%) } \\
\hline Distal & 58 & 53.6 & \multirow{3}{*}{0.796} \\
\hline Middle & 29.6 & 34.8 & \\
\hline Proximal & 12.4 & 11.6 & \\
\hline Solitary kidneys (\%) & 46.9 & 49.3 & 0.773 \\
\hline $\begin{array}{l}\text { Single obstructing ureteral } \\
\text { stone (\%) }\end{array}$ & 91.4 & 88.4 & 0.548 \\
\hline $\begin{array}{l}\text { Median total stones length, } \mathrm{mm} \\
\text { (IQR) }\end{array}$ & $7(5,9)$ & $7(6,9)$ & 0.310 \\
\hline $\begin{array}{l}\text { Median duration of anuria, days } \\
\text { (IQR) }\end{array}$ & $2(2,3)$ & $3(2,3)$ & 0.165 \\
\hline $\begin{array}{l}\text { Median serum creatinine } \\
\text { at presentation, } \mathrm{mg} / \mathrm{dl} \text { (IQR) }\end{array}$ & $4.6(3.8,5.9)$ & $5(3.6,6.2)$ & 0.707 \\
\hline Pre-ureteroscopy dialysis (\%) & 9.9 & 5.8 & 0.548 \\
\hline
\end{tabular}

IQR - inter-quartile range

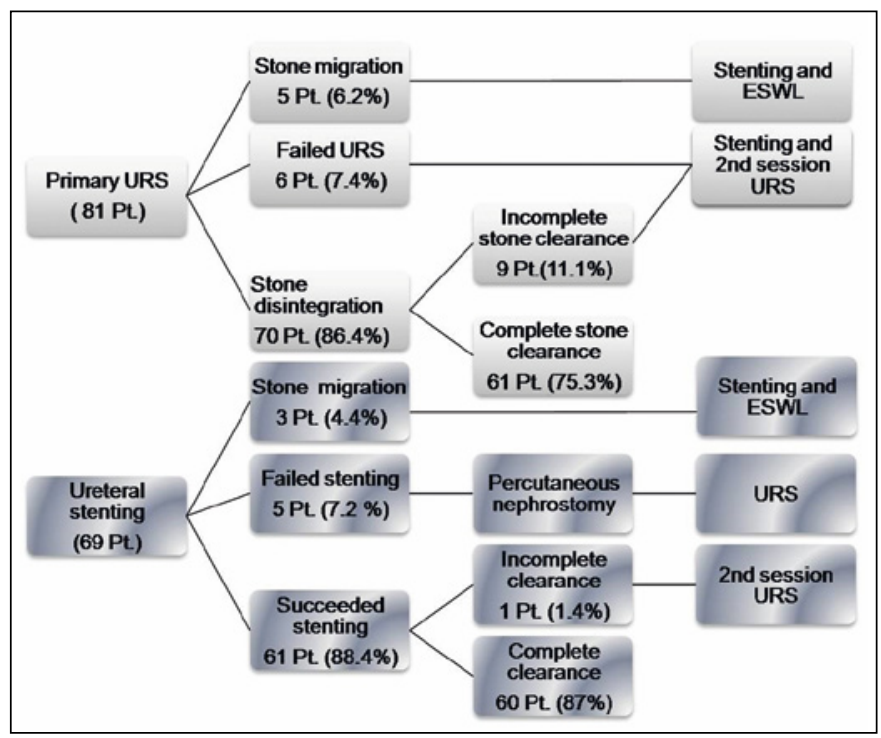

Figure 1. Algorism of patients' management and stone clearance.

ESWL - extracorporeal shock wave lithotripsy ; URS - ureteroscopy

invasive techniques like urinary drainage through a ureteral stent or percutaneous nephrostomy (PCN) should be adopted. Thus, primary ureteroscopy (URS) in this situation may be associated with more complication.

The second issue is the stone impaction, that is not the case in calculus anuria in which the obstruction is of short duration and so primary URS is possible. Third, is related to the urologist and the available 
Table 2. Outcome data for both primary and deferred ureteroscopy (URS) groups

\begin{tabular}{|c|c|c|c|}
\hline & $\begin{array}{l}\text { Primary URS } \\
(\mathrm{N}=81)\end{array}$ & $\begin{array}{l}\text { Deferred URS } \\
\quad(N=69)\end{array}$ & $\mathrm{p}$ Value \\
\hline \multicolumn{4}{|l|}{ Efficacy } \\
\hline$\%$ initial SFR & 75.3 & 87 & 0.097 \\
\hline $\begin{array}{l}\text { Median hospital stays in days } \\
\text { (IQR) }\end{array}$ & $3(3,4)$ & $5(5,6)$ & $<0.001$ \\
\hline $\begin{array}{l}\text { Median maneuvers till } \\
\text { clearance (range) }\end{array}$ & $1(1-5)$ & $2(2-3)$ & $<0.001$ \\
\hline $\begin{array}{l}\text { \% normal renal function } \\
\text { (at 3-month follow-up) }\end{array}$ & 97.5 & 94.2 & 0.414 \\
\hline \multicolumn{4}{|l|}{ Safety } \\
\hline$\%$ Overall complications & 9.9 & 2.9 & 0.109 \\
\hline $\begin{array}{l}\text { *\% Ureteral perforation/ } \\
\text { pyelonephritis }\end{array}$ & 6.2 & 0 & 0.043 \\
\hline $\begin{array}{l}\text { *\% post-operative transient } \\
\text { hematuria }\end{array}$ & 4.9 & 2.9 & 0.090 \\
\hline $\begin{array}{l}\text { *\% post-operative ureteral } \\
\text { stricture }\end{array}$ & 2.5 & 0 & 0.500 \\
\hline Median EGP cost (IQR) & $\begin{array}{c}3200 \\
(3200,3450)\end{array}$ & $\begin{array}{c}4450 \\
(4280,4740)\end{array}$ & $<0.001$ \\
\hline
\end{tabular}

IQR - inter-quartile range

Table 3. Predictors of eventless successful ureteroscopic (URS) treatment of calculus anuria

\begin{tabular}{lcc}
\hline & OR $(95 \% \mathrm{Cl})$ & p Value \\
\hline Age (years) & $1.033(0.977-1.092)$ & 0.251 \\
\hdashline Stone burden & $0.928(0.808-1.066)$ & 0.291 \\
\hdashline Lower ureteral calculi & $13.034(4.074-41.704)$ & $<0.001$ \\
\hline Deferred URS & $2.837(1.074-7.493)$ & 0.035 \\
\hline
\end{tabular}

equipment. The improvement of endoscopic skills, development of small caliber ureteroscopes, modern lithotripters, the use of flexible ureteroscopy (F-URS) to avoid ureteral stone migration and retrograde intra-renal disintegration have allowed more successful and safer endoscopic removal of ureteral stones [6, 7].

Rarely will a patient with unilateral ureteral stone and bilateral functioning kidneys develop anuria in an uncommon condition called reflex anuria. The pathogenesis is still unclear, and many hypotheses have been raised; however, the most widely accepted are two. The first stating that the obstruction of one kidney triggers a reflex spasm of the intrarenal arterioles of both kidneys, leading to a bilateral cessation of glomerular filtration. The second hypothesis states that reflex spasm of both ureters leads to hydronephrosis and an empty bladder [8].

In our study, we did not find ureteral polyp or stricture at the stone site during primary URS and this may be due to the short duration of stone impaction. Mugiya et al. stated that only the duraton of stone impaction showed a significant difference between patients with and without ureteral lesions [9]. Cetti et al. reported $8 \%$ incidence of the tight ureter and in these cases, pre-stenting should be considered and discussed with the patients during counseling [10]. Furthermore, balloon dilatation in such cases may lead to longitudinal cracks in the ureteral mucosa and the resulting extravasation is believed to cause fibrosis [11].

According to the American/ European Urological Association ureteral stones guidelines, the overall ureteroscopic stone-clearance for ureteral stones is $90 \%$ [12]. In the meta-analysis for urgent URS done by Picozzi et al., the overall stone-clearance was $89.5 \%$ with a reasonably low complication rate of $7.6 \%$ [13]. In this study, the stone clearance was $87 \%$ and $75.3 \%$ for deferred and primary URS respectively. Most studies (including ours) reported lower stone clearance rates as the stone becomes more proximal [14].

Ureteral perforation is a well-known intraoperative complication during URS. The literature reported a $0 \%$ to $14 \%$ rate of ureteral perforation and avulsion [14]. Schuster et al. found a significant association of ureteral perforation with an increased operative time [15]. To our mind, most of the ureteral perforation occurred during in situ disintegration of the stone without disimpaction or with the extraction of large stone fragments. In this study, we reported two patients with ureteral stricture after primary URS because of ureteral perforation.

We found that primary URS is cost effective. However, the costs per procedure and especially the reimbursement are different from country to country. In contrary to Chu et al., who reported that preoperative stent placement decreases the cost of ureteroscopy [16]. The operative room time in our center does not affect the cost so that reoperations add more costs to deferred URS in our study. Besides, inpatient costs add more to deferred URS. The cost of the complications we excluded reduced the cost of the primary URS.

Our study has some limitations such as the randomization method, our lack of use of the flexible URS for managing upper ureteral stones, and lack of the long-term follow-up for the ureteral stricture formation.

The deferred URS still being the preferred management for calculus anuria. The primary URS is safe, feasible, cost-effective, with short hospital stay, but is still technically demanding. The perioperative complications are comparable to URS in normouric patients.

\section{CONFLICTS OF INTEREST}

The authors declare no conflicts of interest. 


\section{References}

1. Shokeir AA, Shoma AM, Mosbah A, et al. Noncontrast computed tomography in obstructive anuria: a prospective study. Urology. 2002; 59: 861-864.

2. ElSheemy MS, Shouman AM, Shoukry A, et al. Ureteric stents vs percutaneous nephrostomy for initial urinary drainage in children with obstructive anuria and acute renal failure due to ureteric calculi: a prospective, randomized study. BJU Int. 2015; 115: 473-479.

3. Abdel-Kader MS. Management of calcular anuria in adults caused by ureteric stones: By using ureteroscopy and holmium laser. Arab J Urol. 2011; 9: 179-182.

4. Malek RS. Renal lithiasis: a practical approach. J Urol. 1977; 118: 893-901.

5. Jiang $\mathrm{H}, \mathrm{Wu} \mathrm{Z}$, Ding $\mathrm{Q}$. Ureteroscopy, and holmium: YAG laser lithotripsy as an emergency treatment for acute renal failure caused by impacted ureteral calculi. Urology. 2008; 72: 504-507.

6. Harmon WJ, Sershon PD, Blute ML, Patterson DE, Segura JW. Ureteroscopy: current practice and long-term complications. J Urol. 997; 157: 28-32.

7. Karadag MA, Demir A, Cecen K, Bagcioglu M, Kocaaslan R, Altunrende F. Flexible ureterorenoscopy versus semirigid ureteroscopy for the treatment of proximal ureteral stones: a retrospective comparative analysis of 124 patients. Urol J. 2014; 11: 1867-1872.

8. Hou W, Wen J, Ji Z, Chen J, and Li H. Reflex anuria: an old concept with new evidence. Int Urol Nephrol. 2014; 46: 323-328.

9. Mugiya $\mathrm{S}$, Ito T, Maruyama $\mathrm{S}$, Hadano S, Nagae H. Endoscopic features of impacted ureteral stones. J Urol. 2004; 171; 89-91.

10. Cetti RJ, Biers S, Keoghane SR. The difficult ureter: what is the incidence of pre-stenting? Ann R Coll Surg Engl. 2011; 93: 31-33.

11. Roberts WW, Cadeddu JA, Micali S, Kavoussi LR, Moore RG. Ureteral stricture formation after removal of impacted calculi. J Urol. 1998; 159: 723-726.

12. Preminger GM, Tiselius HG, Assimos DG, et al. 2017 guideline for the management of ureteral calculi. J Urol. 2007; 178: 2418-2434.

13. Picozzi SC, Ricci C, Gaeta M, et al. Urgent ureteroscopy as first-line treatment for ureteral stones: a meta-analysis of 681 patients. Urol Res. 2012; 40: 581-586.

14. Tawfik ER, Bagley DH. Management of upper urinary tract calculi with ureteroscopic techniques. Urology. 1999; 53: 25-31.

15. Schuster TG, Hollenbeck BK, Faerber GJ, Wolf JS, Jr. Complications of ureteroscopy: analysis of predictive factors. J Urol. 2001; 166: 538-540.

16. Chu L, Farris CA, Corcoran AT, Averch TD. Preoperative stent placement decreases the cost of ureteroscopy. Urology. 2011; 78: 309-313. 